\title{
A construção e a compreensão de sentido em discursos por crianças entre 10 e 12 anos
}

\author{
Letícia da Rosa Fregapani ${ }^{1}$ \\ Cristiane Dall Cortivo Lebler ${ }^{2}$
}

\section{RESUMO}

O presente artigo é fruto de uma pesquisa, de igual nome, que partiu da ideia de que compreender a palavra e as possibilidades que ela delimita ao discurso e que este delimita a ela é essencial para o entendimento do próprio discurso. Sendo assim, este artigo se propõe a pensar sobre a construção e a compreensão de sentido da palavra em discursos, com o embasamento da Teoria da Argumentação na Língua de Oswald Ducrot, Jean-Claude Anscombre e Marion Carel. Escolheu-se observar esse processo em alunos com idade entre 10 e 12 anos e que estão no $5^{\circ}, 6^{\circ}$ ou $7^{\circ}$ ano do Ensino Fundamental. Como procedimentos metodológicos, foram realizados estudos teóricos e construção do corpus, a partir do qual houve a elaboração de uma aula introdutória e de um teste. Ambos foram realizados com alunos da faixa etária selecionada e, posteriormente, tiveram seus resultados analisados a fim de encontrar respostas para os objetivos delimitados. Pôde-se constatar que há um olhar crítico dos alunos com relação ao sentido das palavras e das suas diversas possibilidades de significação, mas que ele é, por muitas vezes, encoberto por experiências anteriores com essas palavras, revelando, portanto, uma grande dificuldade, por parte dos alunos, em considerar o contexto discursivo na apreensão do sentido.

Palavras-chave: Teoria da Argumentação na Língua. Construção de sentido. Discurso. Ensino Fundamental.

\begin{abstract}
The present paper is the result of a homonym research arisen from the concept that the understanding of the word and the possibilities it delimits in discourse, and which this discourse delimits in word, is essential for the discourse understanding itself. Therefore, this work aims to reflect upon meaning construction and the understanding of the word in discourse, based on the Theory of Argumentation within Language, by Oswald Ducrot, Jean-Claude Anscombre and Marion Carel. It was chosen to observe this process on students aged between 10 and 12, attending the 5th, 6th or 7th grades of the Elementary School. As methodological procedures, were carried out theoretical studies and a corpus construction, from which an introductory lesson and a test were elaborated. Both were carried out with students in the aforementioned age group, and after the results obtained were analyzed in order to find out answers to the defined objectives. It can be observed that students have a critical view related to the understanding of words and its manifold possibilities of signification. However, this critical view is frequently enshrouded by students' previous experiences with these words, which reveals a great difficulty in considering the discursive context concerning sense apprehension.
\end{abstract}

Keywords: Theory of Argumentation within Language. Meaning construction. Discourse. Elementary School.

\footnotetext{
${ }^{1}$ Aluna do Curso de Letras da Universidade de Santa Cruz do Sul.

${ }^{2}$ Professora do Departamento de Letras na Universidade de Santa Cruz do Sul. <cristianedc@unisc.br>
} 


\section{INTRODUÇÃO}

Conforme avançamos em nosso desenvolvimento cognitivo, vamos adquirindo a linguagem, descobrindo-a diariamente, primeiro as palavras, seus conceitos e seus usos e, depois, as articulando com conectores e com outros termos, em frases e orações mais complexas. Então, vamos ampliando nosso vocabulário e agregando mecanismos ao nosso principal meio de comunicação. E, como sabemos, a comunicação é um dos maiores promotores de nossas descobertas, sendo ela mesma uma grande descoberta. Apropriar-se da capacidade de compreensão e de construção de sentido através das palavras é formar um ponto de vista sobre elas. Saussure afirma que "é o ponto de vista que cria o objeto" (SAUSSURE, 1995, p. 15) e é disso que trata esse artigo: a partir de qual ponto de vista as crianças veem as palavras que elas e seus próximos empregam?

Sob o aporte da Teoria da Argumentação na Língua, nos propusemos a pensar a linguagem nesse contexto, observando um de seus aspectos primordiais de uso da língua, que é a construção e a compreensão de sentido da palavra no discurso. Considerando que o sentido da palavra se constrói no contexto e que uma única palavra pode mudar o sentido de todo um enunciado, buscamos ver esse processo a partir da perspectiva das crianças que estejam em idade escolar e em processo contínuo da aprendizagem da leitura e da escrita.

Tendo em vista que estamos em um curso de licenciatura e que a compreensão da palavra é essencial para o trabalho na área de Letras, concluímos ser importante observá-la junto aos alunos com quem futuramente vamos trabalhar. Então, o nosso objetivo principal foi analisar o modo como as crianças constroem e compreendem o sentido no discurso. Os sujeitos escolhidos para esta pesquisa são alunos que cursam o $5^{\circ}, 6^{\circ}$ ou o $7^{\circ}$ ano do ensino fundamental e que têm entre 10 e 12 anos, por esse ser, respectivamente, o período anterior, de transição e posterior ao encontro dos alunos com os professores exclusivos da área de língua portuguesa. Os objetivos específicos desta pesquisa são: identificar quais critérios são mais utilizados na atribuição de sentido a discursos pelas crianças; observar os principais tipos de construção de sentido elaborados por crianças entre 10 e 12 anos; estabelecer parâmetros entre referenciais teóricos e a vivência de sala de aula, mediante a construção de sentido em discursos.

Como método de desenvolvimento da pesquisa, realizamos a observação das turmas, desenvolvemos uma aula introdutória e aplicamos um teste. No decorrer deste artigo, passaremos 
pelos principais momentos da pesquisa que o originou, revendo os conceitos da Teoria da Argumentação na Língua que o fundamentam, os métodos nele adotados e os materiais produzidos para a aplicação. Por fim, apresentaremos os resultados decorrentes da análise desses dados e as conclusões às quais chegamos por meio deste estudo.

\section{FUNDAMENTAÇÃO TEÓRICA}

A Teoria da Argumentação na Língua, criada por Oswald Ducrot e Jean-Claude Anscombre, com posterior participação de Marion Carel, fundamenta esta pesquisa a partir da ideia de que as palavras somente têm seu sentido construído pelo discurso. Em sua Primeira Conferência, Ducrot afirma que “O valor argumentativo de uma palavra é, por definição, a orientação que essa palavra dá ao discurso” (DUCROT, 1988, p. 51 - tradução nossa) ${ }^{3}$. Sendo assim, a palavra dá ao discurso uma gama de possibilidades adequadas ou não de continuação, ou, nas palavras do teórico, uma gama de encadeamentos possíveis. A real determinância de cada palavra no discurso é confirmada pelo trecho da mesma conferência, em que o autor afirma que "Em resumo, o valor argumentativo de uma palavra é o papel que ela pode desempenhar no discurso.” (DUCROT, 1988, p. 51 - tradução nossa) ${ }^{4}$. Sendo assim, o sentido de uma palavra depende muito mais do seu contexto do que de um rótulo pré-estabelecido, pois “o valor fatual real das palavras é uma espécie de ilusão que se explica mediante algo muito mais profundo que é o argumentativo.” (DUCROT, 1988, p. 89 - tradução nossa) ${ }^{5}$.

A escolha ou não de uma palavra pode alterar totalmente o sentido de um discurso, e cada discurso é único, por ter um novo contexto argumentativo, uma nova situação discursiva, um novo locutor e novos interlocutores. A conclusão é de que a argumentação está na língua, ou seja, de que o sentido está na língua, sendo esta composta por frases que são articuladas no discurso por um locutor. E junto a esse locutor, que é o responsável pela enunciação, estão os enunciadores, que são os responsáveis pelos pontos de vista apresentados. Esses seres discursivos fazem parte do conceito da polifonia, ou seja, as muitas vozes dentro de um mesmo discurso,

\footnotetext{
3 “El valor argumentativo de una palabra es por definición la orientación que esa palabra da al discurso.” (DUCROT, 1988, p. 51)

4 “En resumen, el valor argumentativo de una palabra es el papel que pueda desempeñar en el discurso." (DUCROT, 1988, p. 51)

5 “... el valor factual real de las palabras es una espécie de ilusión que se explica mediante algo mucho más profundo que es lo argumentativo.” (DUCROT, 1988, p. 89).

Revista Jovens Pesquisadores, Santa Cruz do Sul, v.7, n. 2, p. 63-77, jul./dez. 2017.
} 
presentes na forma dos enunciadores, com quem o locutor tem uma relação direta. O locutor é responsável pelo discurso como um todo, mas, através de marcas linguísticas e construções sintáticas, insere pontos de vista que também constituem o sentido do discurso. Tais pontos de vista, que têm como origem os enunciadores, podem ser assumidos pelo locutor, rejeitados, ou podem ganhar sua concordância.

\section{MATERIAIS E MÉTODOS}

Iniciamos a pesquisa pelo estudo teórico e, logo após, realizamos a seleção do corpus. Com esse material em mãos, procedemos à criação da aula introdutória e do teste. Então, visitamos a escola com o intuito de obter a permissão junto à direção e às professoras das turmas envolvidas para realizar o teste. Num momento posterior, retornamos à escola para observar uma aula de Língua Portuguesa de cada turma e para entregar os termos de consentimento livre e esclarecido, que deveriam ser assinados pelos responsáveis dos alunos, caso concordassem com a participação deles nessa pesquisa. Realizamos a aula introdutória e o teste com as três turmas ( $5^{\circ}$, $6^{\circ}$ e $7^{\circ}$ anos). Após a realização dessa etapa, os resultados foram analisados e discutidos para, assim, chegarmos às conclusões que aqui serão apresentadas.

Optamos por estudar a construção de sentido em discursos através de dois meios, que foram o estudo teórico e a aplicação de um teste. Nesse processo, optamos por utilizar o mesmo material com as três turmas, partindo do preceito de que todas elas teriam condições de responder ao teste, porém com níveis distintos de consciência linguística, que seriam observados nos argumentos de suas respostas. Ou seja, partimos de um ideal e buscamos analisar se ele é real e se haveria distinção concreta do desempenho das turmas. O trabalho com o teste em si reuniu vários fatores, como o já mencionado estudo teórico e, também, a realização das observações das turmas e da aula introdutória.

A observação das turmas foi realizada com o intuito de confirmar se a metodologia planejada tanto para a aula introdutória quanto para o teste era adequada à realidade específica de cada turma e, também, de observar os conteúdos trabalhados, a interação da turma etc., e, ao mesmo tempo, começar a criar uma familiaridade com o grupo, que facilitaria as interações posteriores da pesquisadora com os alunos participantes e que elucidaria as dúvidas que estes teriam sobre a sua participação na pesquisa. Já a aula introdutória teve como objetivo principal 
ambientar os alunos com a questão a ser abordada no teste, despertando, assim, um olhar que talvez não se atingiria sem essa motivação, tendo em vista o tempo curto de realização dos exercícios escritos. Como um objetivo secundário, tivemos a intenção de constatar as noções que os alunos traziam consigo e, durante essa análise, fomos atingidos por outra questão, que seria a diferença entre a argumentação oral e a argumentação escrita.

O processo de construção dos materiais foi igualmente importante, pois o sucesso do teste dependia da qualidade dos textos selecionados e da abordagem realizada. Quanto aos textos, buscamos aqueles nos quais poderíamos identificar situações pontuais e interessantes da construção de sentido em discursos, os quais organizamos sob dois interesses: textos para a aula introdutória e textos para o teste. Os textos da aula introdutória deveriam instigar a percepção de que o sentido da palavra se constrói no contexto e os textos do teste deveriam ter situações em que, devido ao contexto, a palavra apresentasse um sentido específico, sendo que na primeira haveria a mediação da bolsista e no segundo não.

Como resultado, construímos uma aula introdutória com os seguintes momentos: conversação sobre a linguagem; leitura e discussão do texto “A causa da chuva”, para mobilizar a ideia de que uma palavra pode ter sentidos diferentes conforme a perspectiva com a qual é observada; contação da história “Os cegos e o elefante”, para compreensão de que não há um significado absoluto, mas vários significados e perspectivas que, juntos, formam algo maior, que é o sentido de uma palavra e de um discurso; distribuição de uma folha para que os alunos explicassem por escrito para alguém que nunca viu uma pedra o que ela é e para que serve; recolhimento das folhas e registro do seu conteúdo no quadro, para discussão com a turma sobre as diversas possibilidades de construção de sentido da palavra “pedra”.

Já o teste foi composto por quatro exercícios, cada um contendo um texto e questões sobre ele. Passemos, agora, a uma análise mais aprofundada dos exercícios: 
Figura 1: Exercício n ${ }^{0} 1$
1. Leia atentamente o texto abaixo:

\section{O Direito do Anzol}

(CAPARELLI, 2008, p. 10)

A linha e o anzol estavam no fundo no rio esperando peixes. Mas a linha parecia descontente.

-Se eu soubesse que você era assim, todo torto, eu não teria vindo pescar, Anzol. Porque eu ando sempre na linha e sou muito direita.

O Anzol não podia falar porque tinha uma isca na boca. Os peixes vinham nadando e seguiam adiante, sem beliscar.

Ora o Anzol ficava parado, ora balançava nas águas claras do rio. O tempo todo ele pensava numa resposta para dar à linha.

Disse, enfim, pelo canto da boca, como os ventríloquos:

-Sei disso, linha, mas se eu fosse direito, não pegaria peixe e eu fui criado para pegar peixes.

A linha deu de ombros e, ao dar de ombros, fez balançar o Anzol e a isca. Um bagre que vinha passando ficou entusiasmado. Deu uma primeira mordida e achou a isca apetitosa. Deu uma segunda beliscada e levou um susto, a isca sumiu de repente, puxada para o alto.

Pouco depois a isca voltou e o bagre, entusiasmado, abocanhou-a e sentiu que uma força irresistível o puxava para o alto.

O pescador tirou o peixe do Anzol e deixou a vara sobre a areia. O Anzol e a Linha, que também tinham levado um susto com a força da fisgada, retomaram o fôlego. Foi então que o Anzol disse para a Linha: -O direito do Anzol é ser torto.

Sobre o texto responda:

A) Marque a opção que completa adequadamente a seguinte frase:

Ao analisar a palavra "DIREITO" da linha 21 podemos dizer que ela...

( ) Tem o mesmo sentido que a palavra CERTO.

( ) É o oposto de ESQUERDO.

( ) É o mesmo da dupla DIREITOS E DEVERES.

( ) Tem o mesmo sentido que a palavra RETO.

B) Explique por que você considera correta a opção que marcou na questão A?

C) Marque a opção que completa adequadamente a seguinte frase:

Ao analisar a palavra "DIREITO" da linha 10 podemos dizer que ela...

( ) Tem o mesmo sentido que a palavra CERTO.

( ) É o oposto de ESQUERDO.

( ) É o mesmo da dupla DIREITOS E DEVERES.

( ) Tem o mesmo sentido que a palavra RETO.

D) Explique por que você considera correta a opção que marcou na questão C?

Fonte: Exercício elaborado pelas autoras

O objetivo do primeiro exercício era trabalhar a possibilidade de que uma mesma palavra em um mesmo texto pode ter diferentes sentidos construídos em diferentes contextos. Para tal, selecionamos a fábula “O direito do anzol” de Sérgio Caparelli, na qual a palavra direito é empregada com diferentes sentidos, que são compreendidos na linearidade do texto. Identificamos duas ocorrências dessa palavra e, como esse seria o primeiro exercício, escolhemos formular as questões em formato de múltipla escolha, mas os alunos também teriam de justificar Revista Jovens Pesquisadores, Santa Cruz do Sul, v.7, n. 2, p. 63-77, jul./dez. 2017. 
a sua escolha. Sendo assim, demarcamos os enunciados e apresentamos possíveis sentidos para a palavra direito em cada um deles. Para chegar à resposta, os alunos deveriam analisar as possibilidades, olhando para o discurso e, mais especificamente, para os enunciados que precediam a palavra. A análise do trecho da questão A presumia que, inicialmente, se observasse as opções e, de forma eliminatória, se fosse constatando que nem a questão da direção (É o oposto de ESQUERDO) e tampouco a noção cidadã (É o mesmo da dupla DIREITOS E DEVERES) eram adequadas ao contexto. Além disso, apontava para a necessidade de o aluno fazer um exercício de substituição e observar que entre certo e reto o sentido mais adequado a esse contexto seria certo. Já o segundo enunciado necessitava de uma análise dos discursos anteriores, mais especificamente das linhas 3 e 4, onde é criada uma oposição entre torto e direita, o que tornaria direita um sinônimo de reto, sendo essa a resposta adequada.

Figura 2: Exercício no 2

2. Leia atentamente:

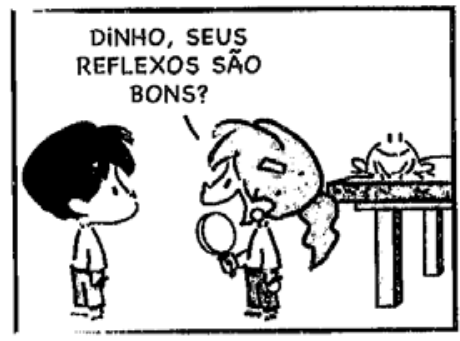

Responda às seguintes questões sobre a tirinha:

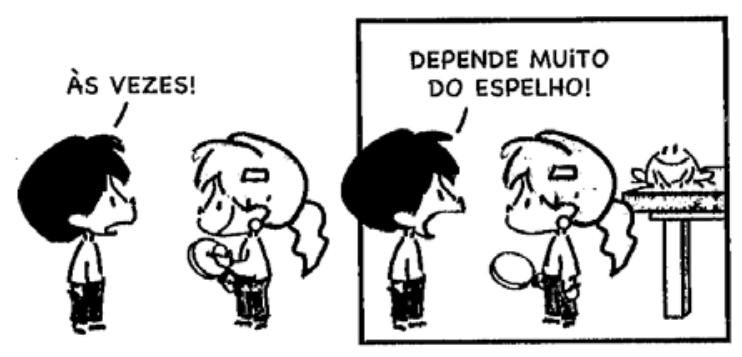

(BECK, 2015, p. 13)

A) De que tipo de reflexo o menino está falando? Por quê?

B) De que tipo de reflexo a menina está falando? Por quê?

C) Se a palavra "bons" do $1^{\circ}$ quadrinho for substituída por "bonitos" o sentido da palavra "reflexo" para o menino e para a menina será o mesmo? Por quê?

\section{Fonte: Exercício elaborado pelas autoras}

O objetivo do segundo exercício era identificar os dois sentidos levantados para a palavra em questão e observar no discurso os elementos contribuintes para a construção desses sentidos. Para tal, escolhemos uma tirinha do Armandinho; nela cada personagem emprega um sentido para a palavra reflexo. A ideia inicial era que os alunos identificassem os dois sentidos e que, posteriormente, fizessem um trabalho de substituição lexical e de criação de hipóteses. Não é necessário recorrer à linguagem não verbal (imagens da raquete e da mesa de ping-pong) para compreender o discurso, pois o próprio emprego do adjetivo nos faz entender que a menina fala dos reflexos da agilidade, e o menino, dos reflexos no espelho, porque este o caracteriza como 
bonitos (relativo à beleza portanto reflexo do espelho) e aquela como bons (relativo à qualidade de movimento portanto reflexos da agilidade). Caso essa noção não fosse atingida através das questões A e B, ela seria instigada com a questão C.

\section{Figura 3: Exercício no 3}

3. Leia atentamente:
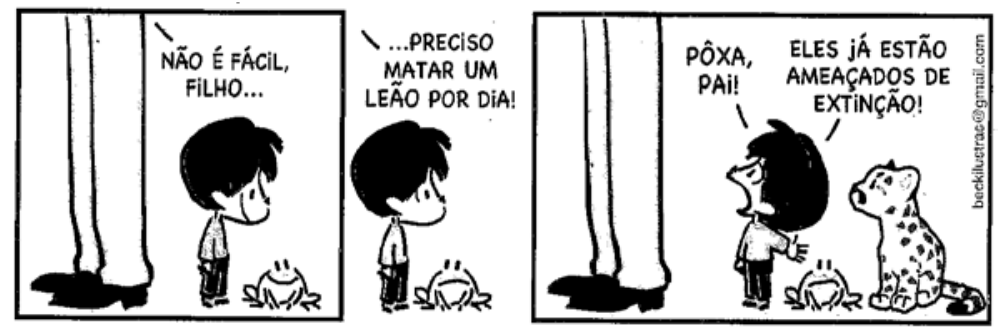

(BECK, 2015, p. 39)

A) Na tirinha acima o que significa "matar um leão por dia” para o pai? E o que significa para o filho? Por quê?

\section{Fonte: Exercício elaborado pelas autoras}

O terceiro exercício pretendia observar como os alunos lidam com as expressões cristalizadas. Para tal, selecionamos uma tirinha do Armandinho, na qual um personagem emprega uma expressão cristalizada no seu sentido figurado e o outro a compreende no seu sentido literal. A tarefa dos alunos era identificar os sentidos da expressão, segundo as perspectivas colocadas, e justificar por que houve diferenças.

\section{Figura 4: Exercício n ${ }^{0} 4$}

4. Leia atentamente:

\section{A raposa e as uvas}

(LOBATO, [19--], P. 47)

Certa raposa esfaimada encontrou uma parreira carregadinha de lindos cachos maduros, coisa de fazer vir água à boca. Mas tão altos que nem pulando.

O matreiro bicho torceu o focinho.

- Estão verdes - murmurou. - Uvas verdes, só para cachorro.

E foi-se.

Nisto deu o vento e uma folha caiu.

A raposa ouvindo o barulhinho voltou depressa e pôs-se a farejar...

Quem desdenha quer comprar.

$[\ldots]$

A) Com base no comportamento da raposa na fábula “A raposa e as uvas”, explique o significado da palavra “desdenhar”:

Fonte: Exercício elaborado pelas autoras 
Já no quarto exercício, os alunos deveriam identificar o sentido de uma palavra, possivelmente não usual para eles, a partir de seu contexto. Para tal, escolhemos a fábula “A raposa e as uvas”, de Monteiro Lobato, na qual, ao longo do texto, o sentido da palavra desdenhar é construído; os alunos teriam de ler o texto e definir o sentido da palavra. O que poderia ser feito pela listagem dos passos da história: a raposa quer as uvas e não pode tê-las, então diz não querê-las, mas continua querendo, já que retorna quando ouve o barulho de algo caindo e imagina que possam ser as uvas. Ou seja, quem fala mal de algo na verdade o quer.

Antes da aplicação do teste nas turmas participantes da pesquisa, realizamos a pilotagem do material com um aluno de $6^{\circ}$ ano, quando realizamos todos os passos previstos na pesquisa (aula introdutória e teste), porém acrescentamos, ao término do teste, uma conversa com esse aluno sobre suas impressões. Durante o trabalho, percebemos uma dificuldade desse aluno em colocar no papel aquilo que estava argumentando oralmente, mas também percebemos que ele conseguiu atingir, na maioria das vezes, o cerne das questões. E, inclusive, argumentou sobre a construção de sentido de um modo geral, afirmando que “toda palavra tem dois lados”, o que confirma não a teoria exata que nos fundamenta, mas o princípio de uma reflexão sobre a variedade de sentidos de uma única palavra.

É importante ressaltar que a aula introdutória e o teste foram aplicados em sequência e no mesmo dia, ocupando dois períodos de aula de cada turma. Após esse processo, passamos à análise das respostas dadas aos testes por aqueles alunos dos quais obtivemos a permissão dos responsáveis para participar da pesquisa. Apesar de todos os alunos terem participado da aula introdutória e do teste, só tiveram seus resultados analisados aqueles cujos responsáveis permitiram-no, através da assinatura do termo de consentimento livre e esclarecido. Essa foi uma das dificuldades encontradas, pois uma parcela considerável dos responsáveis pelos alunos não concedeu a permissão para que os resultados produzidos pelos alunos fossem analisados e, portanto, estes só realizaram as atividades como exercício de aula. Consequentemente, tivemos um total de 18 alunos participantes, sendo onze do $5^{\circ}$ ano, seis do $6^{\circ}$ ano e um do $7^{\circ}$ ano. Outra dificuldade foi a delimitação da idade, pois, ao definirmos a faixa etária do estudo entre 10 e 12 anos, não pudemos utilizar as respostas dos alunos do $7^{\circ}$ ano que eram maiores de 12 anos e que nos concederam a permissão, que foram dois alunos. Sendo assim, os resultados do $7^{\circ}$ ano tiveram uma análise limitada mediante a situação, o que acreditamos não comprometer totalmente os resultados desta pesquisa, pois, no momento da aula introdutória, a maioria dos Revista Jovens Pesquisadores, Santa Cruz do Sul, v.7, n. 2, p. 63-77, jul./dez. 2017. 
alunos participou e pudemos observar que os colegas de mesma faixa etária demonstraram um nível de ideias semelhante ao do aluno aqui analisado.

\section{RESULTADOS}

Com o objetivo de realizar a análise dos dados, as respostas foram organizadas em tabelas, de acordo com as turmas $\left(5^{\circ}, 6^{\circ}\right.$ e $7^{\circ}$ ano), e internamente por aluno (identificado por um número). Após e durante a análise dessas primeiras tabelas, seguimos em dois movimentos: o de registrar as observações feitas a respeito das respostas dos alunos e o de construir tabelas síntese da porcentagem de respostas adequadas de cada turma em cada exercício e da porcentagem de respostas adequadas de cada aluno no teste como um todo. Sendo assim, o que nos auxiliará nesse relato serão principalmente os produtos desse segundo momento e alguns exemplos de respostas dos participantes.

Se analisarmos as tabelas síntese de cada exercício, apresentadas a seguir, podemos inicialmente chegar a dois pontos: a diferença de desempenho dos alunos entre as questões e entre as turmas. É importante ressaltar que não procuramos respostas certas ou erradas para as questões, mas, sim, respostas que estivessem adequadas ao contexto da pergunta.

\section{Tabela 1: Desempenho das turmas (porcentagem de respostas adequadas por}

\section{questão)}

\begin{tabular}{|c|c|c|c|c|c|c|c|c|}
\hline \multicolumn{9}{|c|}{ EXERCÍCIO 1} \\
\hline \multirow{3}{*}{ TURMA } & \multicolumn{8}{|c|}{ QUESTÕES } \\
\hline & \multicolumn{2}{|l|}{ A } & \multirow{2}{*}{\multicolumn{2}{|c|}{$\begin{array}{c}\text { B } \\
\begin{array}{c}\text { Justificaram } \\
\text { adequadamente }\end{array}\end{array}$}} & \multicolumn{2}{|l|}{$\mathrm{C}$} & \multicolumn{2}{|r|}{ D } \\
\hline & \multicolumn{2}{|c|}{ Marcaram a 1ªpção } & & & \multicolumn{2}{|c|}{ Marcaram a $4^{\text {a }}$ opção } & \multicolumn{2}{|c|}{$\begin{array}{c}\text { Justificaram } \\
\text { adequadamente }\end{array}$} \\
\hline $5^{\circ}$ ANO & \multicolumn{2}{|l|}{$0 \%$} & \multicolumn{2}{|r|}{$0 \%$} & \multicolumn{2}{|c|}{$36,36 \%$} & \multicolumn{2}{|r|}{$9,09 \%$} \\
\hline $6^{\circ}$ ANO & \multicolumn{2}{|c|}{$16,66 \%$} & \multicolumn{2}{|r|}{$16,66 \%$} & \multicolumn{2}{|l|}{$50 \%$} & \multicolumn{2}{|r|}{$50 \%$} \\
\hline \multirow{2}{*}{$7^{\circ}$ ANO } & \multicolumn{2}{|l|}{$0 \%$} & \multirow{2}{*}{\multicolumn{2}{|c|}{$\begin{array}{c}0 \% \\
\text { EXERCÍCIO }\end{array}$}} & \multicolumn{2}{|l|}{$100 \%$} & \\
\hline & & & & & \multicolumn{2}{|r|}{$100 \%$} \\
\hline & \multicolumn{8}{|c|}{ QUESTÕES } \\
\hline & \multicolumn{3}{|c|}{$\mathbf{A}$} & \multicolumn{2}{|c|}{ B } & \multicolumn{3}{|c|}{$\mathrm{C}$} \\
\hline TURMA & $\begin{array}{l}\text { Afirmaram se } \\
\text { tratar do } \\
\text { reflexo do } \\
\text { espelho }\end{array}$ & $\begin{array}{r}\text { Justifi } \\
\text { adequa }\end{array}$ & & $\begin{array}{l}\text { Afirmaram se } \\
\text { tratar do } \\
\text { reflexo } \\
\text { referente à } \\
\text { agilidade }\end{array}$ & $\begin{array}{c}\text { Justificaram } \\
\text { adequadamente }\end{array}$ & \begin{tabular}{|r} 
Afirma \\
a subs \\
do ad \\
caus \\
concor \\
ent \\
perso
\end{tabular} & $\begin{array}{l}\text { n que } \\
\text { iç̧ão } \\
\text { ivo } \\
\text { a a } \\
\text { ncia } \\
\text { ss } \\
\text { sens } \\
\end{array}$ & $\begin{array}{c}\text { Justificaram } \\
\text { adequadament } \\
\text { e }\end{array}$ \\
\hline
\end{tabular}




\begin{tabular}{|c|c|c|c|c|c|c|}
\hline $5^{\circ}$ ANO & $45,45 \%$ & $9,09 \%$ & $18,18 \%$ & $18,18 \%$ & $9,09 \%$ & $9,09 \%$ \\
\hline $6^{\circ}$ ANO & $33,33 \%$ & $33,33 \%$ & $16,66 \%$ & $0 \%$ & $50 \%$ & $50 \%$ \\
\hline $7^{\circ}$ ANO & $100 \%$ & $100 \%$ & $100 \%$ & $0 \%$ & $100 \%$ & $100 \%$ \\
\hline \multicolumn{7}{|c|}{ EXERCÍCIO 3} \\
\hline \multirow[b]{3}{*}{ TURMA } & \multicolumn{6}{|c|}{ QUESTÕES } \\
\hline & \multicolumn{6}{|c|}{ A } \\
\hline & \multicolumn{2}{|c|}{$\begin{array}{c}\text { Afirmaram que se tratava de } \\
\text { uma expressão sobre } \\
\text { trabalho pesado }\end{array}$} & \multicolumn{2}{|c|}{$\begin{array}{l}\text { Afirmaram que se tratava de } \\
\text { uma expressão literal sobre } \\
\text { cometer um crime }\end{array}$} & \multicolumn{2}{|c|}{ Justificaram adequadamente } \\
\hline $5^{\circ}$ ANO & \multicolumn{2}{|c|}{$27,27 \%$} & \multicolumn{2}{|c|}{$45,45 \%$} & \multicolumn{2}{|c|}{$0 \%$} \\
\hline $6^{\circ}$ ANO & \multicolumn{2}{|c|}{$33,33 \%$} & \multicolumn{2}{|c|}{$33,33 \%$} & \multicolumn{2}{|c|}{$16,66 \%$} \\
\hline $7^{\circ}$ ANO & \multicolumn{2}{|c|}{$100 \%$} & \multicolumn{2}{|c|}{$100 \%$} & \multicolumn{2}{|c|}{$0 \%$} \\
\hline \multicolumn{7}{|c|}{ EXERCÍCIO 4} \\
\hline \multirow{3}{*}{ TURMA } & \multicolumn{6}{|c|}{ QUESTÃO } \\
\hline & \multicolumn{6}{|c|}{ A } \\
\hline & \multicolumn{6}{|c|}{ Apresentaram uma definição adequada para a palavra desdenhar } \\
\hline $5^{\circ}$ ANO & \multicolumn{6}{|c|}{$0 \%$} \\
\hline $6^{\circ}$ ANO & \multicolumn{6}{|c|}{$0 \%$} \\
\hline $7^{\circ}$ ANO & \multicolumn{6}{|c|}{$100 \%$} \\
\hline
\end{tabular}

Fonte: tabela elaborada pelas autoras

Quanto ao exercício 1, podemos perceber que as questões C e D tiveram uma porcentagem de respostas adequadas maior que as questões A e B, o que entendemos ser um sinal de que houve a compreensão da oposição direito (portanto reto) $\mathrm{X}$ torto, como podemos comprovar na resposta de um dos alunos do $6^{\circ}$ ano, na qual ele afirma, a respeito do anzol, que Se ele fosse reto ele não pegaria peixe ${ }^{6}$, utilizando, assim, um argumento por substituição, cuja estratégia está apoiada sobre a semântica de outras palavras, relacionandoas ao contexto em questão. Um aluno do $5^{\circ}$ ano fez a seguinte afirmação, na mesma questão: Por que eu acho se ele fosse certo não teria como pegar os peixes por que ele foi feito para isso, na qual ele acaba reproduzindo a mesma construção do texto e não a explicando, o que consideramos como resposta inadequada, pois ele não responde à pergunta. Outro aspecto interessante é a menção feita ao "eu", o que foi uma constante dentro das respostas, principalmente do $5^{\circ}$ ano, representando, assim, uma retomada muito maior da experiência pessoal com as palavras do que um olhar para o contexto específico do discurso.

O exercício 2, apesar de ser mais extenso, foi um exercício em que os alunos

\footnotetext{
${ }^{6}$ As respostas dos alunos foram transcritas com fidelidade. Revista Jovens Pesquisadores, Santa Cruz do Sul, v.7, n. 2, p. 63-77, jul./dez. 2017.
} 
tiveram, de um modo geral, um desempenho considerável, em que souberam olhar para o texto e perceber a possibilidade de mais de um sentido para uma mesma palavra. Os participantes da pesquisa conseguiram até mesmo justificar a sua resposta através de uma análise da relação entre o substantivo e os adjetivos que o poderiam acompanhar, processo esse que, inclusive, um dos alunos do $5^{\circ}$ ano conseguiu realizar. Esse aluno, ao ser questionado se, ao substituir bons por bonitos o sentido seria o mesmo para os dois personagens, afirmou que sim. Porque reflexo do joelho não é bonito Reflexo do espelho pode ser bonito. E se olharmos a complexidade das questões nesse exercício, podemos considerar que a questão $\mathrm{C}$ tem um grau de complexidade maior, mas que, em contrapartida a isso, os alunos do $6^{\circ}$ ano tiveram um melhor resultado nessa questão em um comparativo com as demais.

Sobre o exercício 3, podemos constatar um bom percentual de alunos que conseguiram identificar o sentido da expressão empregada individualmente pelos personagens da tirinha. Com um único enunciado, um aluno do $6^{\circ}$ ano identificou os sentidos e justificou da seguinte forma: Para o pai se trata de ser difícil e para o filho é um leão mesmo, porque tem duplo sentido. De forma objetiva, consegue esclarecer as diferenças e trazer à tona um conceito interessante, que é o da possibilidade de duplo sentido. Mas essa foi uma exceção, pois percebemos uma dificuldade por parte dos alunos em justificar suas escolhas.

Na maioria das vezes, as justificativas apresentaram: respostas embasadas no “Eu”, respostas desconexas, dificuldade em considerar o contexto, argumentos por substituição, o uso do enunciado da questão na justificativa, argumentos de que só mudaria uma palavra, que é assim e pronto, entre outros. Mas também houve respostas muito satisfatórias e até mesmo curiosas, como: criatividade na hora de propor o significado dos termos, consideração da possibilidade de duplo sentido, argumentos captando peculiaridades dos textos e explicando em palavras simples regras de concordância.

Quanto ao desempenho de um modo geral, também vemos que houve grande dificuldade no exercício 4, no qual a tarefa era identificar o significado de uma palavra, possivelmente desconhecida para os alunos, através do seu contexto. E os resultados mostram que foi só no $7^{\circ}$ ano que os alunos conseguiram responder ao exercício. $\mathrm{O}$ aluno definiu a palavra desdenhar do seguinte modo: Quem “murmurar" quer comprar. Isto 
significa que ele reclama da uva mais ainda quer come-la.

Ao analisarmos o desempenho de cada aluno, chegamos a um resultado um pouco preocupante (Tabela 2), pois temos alunos que ou tiveram um desempenho muito baixo ou não pontuaram em nenhuma questão. $\mathrm{E}$, ao mesmo tempo, temos alunos tanto do $5^{\circ}$, como do $6^{\circ}$ e do $7^{\circ}$ ano com pontuação maior que $50 \%$.

\section{Tabela 2: Porcentagem de respostas adequadas por aluno}

\begin{tabular}{|c|c|c|}
\hline & Número do aluno & Aproveitamento \\
\hline \multirow{11}{*}{$5^{\circ}$ ANO } & 1 & $14,28 \%$ \\
\hline & 2 & $50 \%$ \\
\hline & 3 & $0 \%$ \\
\hline & 4 & $14,28 \%$ \\
\hline & 5 & 21,42 \\
\hline & 6 & $14,28 \%$ \\
\hline & 7 & $0 \%$ \\
\hline & 8 & $35,71 \%$ \\
\hline & 9 & $14,28 \%$ \\
\hline & 10 & $0 \%$ \\
\hline & 11 & $7,14 \%$ \\
\hline \multirow{6}{*}{$6^{\circ}$ ANO } & 12 & $14,28 \%$ \\
\hline & 13 & $57,14 \%$ \\
\hline & 14 & $14,28 \%$ \\
\hline & 15 & $28,57 \%$ \\
\hline & 16 & $57,14 \%$ \\
\hline & 17 & $0 \%$ \\
\hline $7^{\circ}$ ANO & 18 & $71,42 \%$ \\
\hline
\end{tabular}

Fonte: tabela elaborada pelas autoras

Existe uma série de fatores implicados nesses resultados e, até mesmo, o fato de ser uma resposta escrita e não oral pode apresentar um grau maior de dificuldade para os alunos, pois estes participaram ativamente da aula introdutória, comentando e argumentando acerca dos questionamentos. Pudemos perceber que há, sim, por parte dos alunos, um olhar crítico sobre a construção de sentido em discursos, mas que, em boa parte das vezes, ele é mascarado pelas experiências anteriores com as palavras, fazendo com que essa vivência se sobreponha à necessidade de se considerar o contexto específico em que a palavra está e que, portanto, esse é o principal critério e forma de construção utilizado pelos alunos, denotando uma certa ausência de reflexão linguística que considere o texto como ponto de partida. 


\section{CONCLUSÃO}

Um dos objetivos iniciais deste trabalho era identificar quais critérios são mais utilizados pelas crianças entre 10 e 12 anos na atribuição de sentido a discursos. E nossa conclusão é que a consideração do contexto, que, segundo nosso aporte teórico, deveria ser primordial, é sobreposta pela experiência linguística dos alunos, quando eles optam por justificar suas análises embasados na perspectiva do "eu" e também acabam não lendo o discurso de uma forma mais profunda, tendo em vista a sua unidade. Também pretendíamos observar os principais tipos de construção de sentido elaborados pelos sujeitos da pesquisa, o que, em um primeiro momento, nos revelou certa redundância entre o primeiro objetivo e esse. Novamente, compreendemos que os alunos, em suas respostas, empregaram as palavras de modo descontextualizado e fizeram construções sintáticas simples. Mas, se pensarmos na atividade realizada sobre os sentidos da palavra pedra, desenvolvida na aula introdutória, podemos afirmar que, sim, eles conseguem captar outras possibilidades de construção de sentido.

Por fim, tínhamos como tarefa estabelecer parâmetros entre referenciais teóricos e a vivência de sala de aula quanto ao assunto construção de sentido, o que concluímos ter ficado muito claro durante todo o processo, pois os conceitos da Teoria da Argumentação na Língua nos auxiliaram não só na elaboração dos materiais, mas também na aplicação do teste, na mediação da aula introdutória e na análise dos dados. O que comprova que, mesmo sem mencionar nomes teóricos em sala de aula, a fundamentação teórica é muito enriquecedora do processo docente. $\mathrm{E}$ aquilo que permeou todo esse trabalho: pensar a construção e a compreensão de sentido no discurso através da aplicação de teste, não só nos trouxe respostas, como também nos trouxe novas perguntas que, talvez, não tenhamos conseguido responder nesse momento, mas que certamente permearão nossos próximos trabalhos.

O que fica é a constatação de que, sim, há uma necessidade de se trabalhar, com os alunos, mais a percepção da construção de sentido nos discursos, considerando que essa é uma forma de maior compreensão da linguagem, tanto na enunciação escrita quanto na oral, fazendo com que os alunos se expressem e compreendam melhor o que leem e, portanto, tenham um maior domínio da linguagem, o que geraria pessoas mais bem formadas e conhecedoras dos processos sociais, que é um dos objetivos da escola. Sendo assim, percebemos uma possibilidade de continuação deste trabalho, agora com resultados palpáveis em mãos. Essa continuidade se 
daria tanto pela consideração de outros fatores relativos aos sujeitos da pesquisa, como fatores socioculturais, como pela produção de um material que buscasse trabalhar as dificuldades reveladas por este estudo. Algo que nos permitisse dar um retorno, até mesmo aos voluntários desta pesquisa, e que nos proporcionaria pensar metodologicamente em como sanar as dificuldades identificadas através do aporte teórico e do teste, o que seria, portanto, a criação de um material didático sobre a compreensão e a construção de sentido em discursos.

\section{REFERÊNCIAS}

BECK, A. Armandinho Seis. Florianópolis: A.C. Beck, 2015.

CAPPARELLI, S. 30 fábulas contemporâneas para crianças. Porto Alegre: L\&PM, 2008. 70 p.

DUCROT, O. Polifonia y argumentación. Calle: Universidad del Valle-Cali, 1988.

LOBATO, M. Fábulas. 12. ed. São Paulo: Brasiliense, [19--]. 164 p.

SAUSSURE, F. de. Curso de lingüística geral. 18. ed. São Paulo: Cultrix, 1995. 279 p. 